\title{
Case Report. Recurrence of increased intracranial pressure with antiretroviral therapy in an AIDS patient with cryptococcal meningitis
}

\author{
Fallbericht. Wiederanstieg des Intrakranialdrucks bei antiretriviraler \\ Therapie an einem AIDS-Patienten mit Cryptococcus-Meningitis
}

\author{
S. K. Cinti, Wendy S. Armstrong and Carol A. Kauffman
}

Key words. Cryptococcosis, meningitis, AIDS, HAART, intracranial pressure.

Schlüsselwörter. Cryptococcose, Meningitis, AIDS, HAART, Intrakranialdruck.

Summary. We present the case of an AIDS patient with cryptococcal meningitis who, after an excellent clinical and mycological response to antifungal therapy, developed an exacerbation of signs and symptoms, including elevated intracranial pressure and an increase in cerebrospinal fluid cryptococcal antigen and white blood cells, following the initiation of highly active antiretroviral therapy (HAART). Cultures yielded no growth and the patient responded to repeated lumbar punctures without changing or intensifying antifungal therapy. To our knowledge, this is the first report of symptomatic elevated intracranial pressure occurring during HAARTrelated immune recovery in a patient with cryptococcal meningitis. Exacerbation of symptoms does not necessarily reflect mycological failure that requires a change in antifungal therapy, but may relate to acutely increased intracranial pressure that will respond to simple measures, such as repeated lumbar punctures.

Zusammenfassung. Es wird ein AIDS-Patient mit Cryptococcus-Meningitis vorgestellt, der klinisch

Division of Infectious Diseases, Veterans Affairs Ann Arbor Healthcare System, University of Michigan Medical School, Ann Arbor, Michigan, USA.

Correspondence: Professor Dr Carol A. Kauffman, VA Medical Center, 2215 Fuller Rd., Ann Arbor, MI 48105, USA. Tel: +1-734-761-7984 Fax: +1-734-769-7039; E-mail: ckauff@umich.edu und mykologisch exzellent auf die antimykotische Therapie ansprach, dann aber in der Symptomatik wieder exazerbierte mit erhöhtem Liquordruck und Zunahme von Cryptococcus-Antigen und weißen Blutzellen im Liquor nach Beginn einer hochaktiven antiretroviralen Therapie (HAART). Kulturen ergaben kein Wachstum, und der Patient sprach auf Lumbalpunktionen an, ohne dass die antimykotische Chemotherapie geändert oder intensiviert wurde. Nach unserer Kenntnis ist dies der erste Bericht einer symptomatischen Liquordruckzunahme unter HAART-bezogener Immunholung bei Cryptococcus-Meningitis. Eine solche Exazerbation der Symptomatik spiegelt nicht notwendigerweise einen mykologischen Fehlschag wider, der einer Änderung der antimykotischen Chemotherapie bedarf, sondern kann auf akut erhöhtem Liquordruck beruhen, der mit einfachen Maßnahmen, wie wiederholten Lumbalpunktionen, korrigierbar ist.

\section{Introduction}

Cryptococcal meningitis is a common AIDSdefining opportunistic infection in patients with HIV infection $[1,2]$. In this population, infection is characterized by a large burden of fungal organisms associated with a minimal immune and inflammatory response [3]. Elevated intracranial pressure (ICP) is commonly noted and has been associated with a poor prognosis [3-5]. 
The advent of highly active antiretroviral therapy (HAART) has resulted in a dramatic decrease in the incidence of opportunistic infections, including cryptococcosis, in HIV-infected patients [6]. The immune recovery after treatment with HAART has led to reports of paradoxical worsening of symptoms and development of opportunistic infections [7, 8]. We describe a patient with recurrence of symptoms of cryptococcal meningitis, including elevated ICP, after institution of HAART.

\section{Case report}

A 33-year-old man presented on 10 December, 1997 with a 5-week history of headaches, emesis, a weight loss of 10 pound, photophobia, aphasia and periodic left face and lower extremity numbness. On admission he was febrile to $37.9^{\circ} \mathrm{C}$, lethargic, had garbled speech and mild rightsided weakness. Oropharyngeal candidosis and cervical adenopathy were noted. A computerized tomography (CT) scan of his head showed only diffuse atrophy. A lumbar puncture revealed an opening pressure of $35 \mathrm{~cm} \mathrm{H}_{2} \mathrm{O}$; the cerebrospinal fluid (CSF) showed 50 white blood cells (WBC) $\mu \mathrm{l}^{-1}$ (90\% mononuclear cells), glucose $35 \mathrm{mg} \mathrm{dl}^{-1}$ and protein $214 \mathrm{mg} \mathrm{dl}^{-1}$ (Fig. 1). The India ink preparation and CSF cryptococcal antigen (CRAG) were reported as positive and cultures yielded Cryptococcus neoformans. An HIV enzyme-linked immunosorbent assay and confirmatory Western blot assay were positive. Amphotericin B therapy was initiated and the patient was transferred to the Ann Arbor Veterans Affairs Medical Center.

On arrival, on 24 December, 1997, his temperature was $38.3^{\circ} \mathrm{C}$; the neurologic examination, including a fundoscopic examination, was normal. Lumbar puncture revealed that the opening pressure had decreased to $18 \mathrm{~cm} \mathrm{H}_{2} \mathrm{O}$; CSF WBC were $91 \mu^{-1}$ (96\% mononuclear cells),

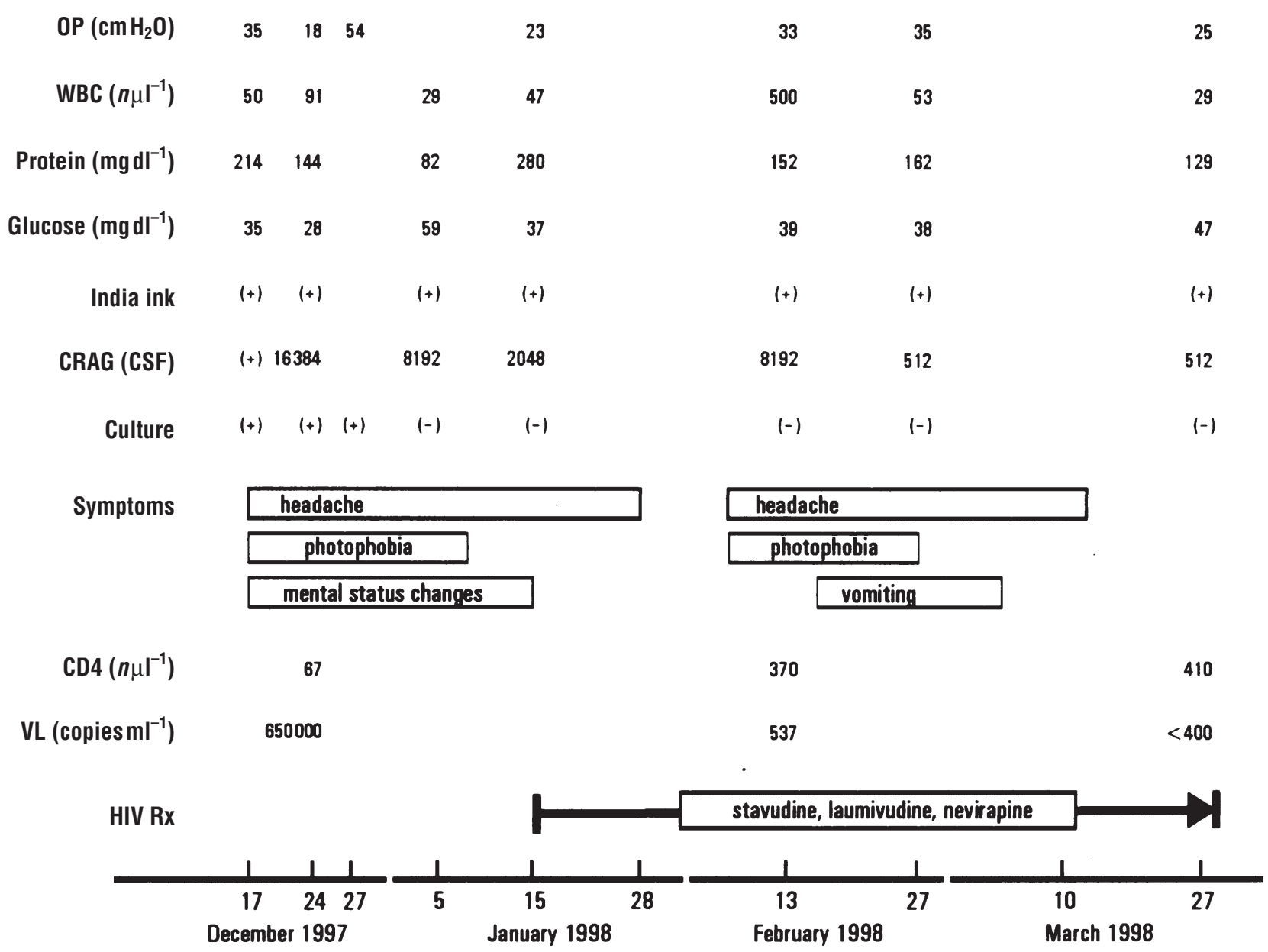

Figure 1. Clinical course of cryptococcal meningitis in a patient with HIV infection illustrating worsening of intracranial pressure, white blood cell count (WBC), protein and cryptococcal antigen (CRAG) following initiation of antiretroviral therapy. OP, opening pressure; CSF, cerebrospinal fluid; $\mathrm{VL}$, viral load; Rx, treatment. 
protein $144 \mathrm{mg} \mathrm{dl}^{-1}$ and glucose $28 \mathrm{mg} \mathrm{dl}^{-1}$. The CSF cultures remained positive. CSF and serum CRAG titres were both 1:16384 and cultures of CSF again yielded Cr. neoformans. The CD4 cell count and viral load were $67 \mathrm{\mu l}^{-1}$ and 650000 copies $\mathrm{ml}^{-1}$, respectively. Amphotericin B was continued at a dose of $0.7 \mathrm{mg} \mathrm{kg}^{-1}$ per day and flucytosine (100 $\mathrm{mg} \mathrm{kg}^{-1}$ per day) was added to his regimen.

Throughout his course, the patient's mental status waxed and waned and he complained of severe headaches. Follow-up lumbar punctures revealed persistently elevated ICP as high as $54 \mathrm{~cm} \mathrm{H}_{2} \mathrm{O}$; subsequently a ventriculostomy was placed to monitor and more consistently maintain his ICP within the normal range. After 10 days, his ICP remained stable at approximately $23 \mathrm{~cm} \mathrm{H}_{2} \mathrm{O}$ and the ventriculostomy was removed. Two weeks after initiation of antifungal therapy his CSF cultures yielded no growth and after 3 weeks, on 15 January, 1998 the regimen was changed to fluconazole $(400 \mathrm{mg}$ daily). Stavudine (40 mg twice daily), lamivudine (150 mg twice daily) and nevirapine (200 mg twice daily) were initiated.

The patient did well until 3 weeks after starting HAART when photophobia, headaches and confusion recurred. A head CT was unchanged, but a repeat lumbar puncture on 13 February, 1998 revealed an increase in the opening pressure to $33 \mathrm{~cm} \mathrm{H}_{2} \mathrm{O}$ and an elevated CSF WBC and CRAG titre (Fig. 1). The CSF cultures remained negative. At that time, his CD4 cell count had boosted to $370 \mu \mathrm{l}^{-1}$ with a $3.1 \mathrm{log}$ reduction in viral load to 537 copies $\mathrm{ml}^{-1}$. Fluconazole was continued at the same dose and the patient was followed closely. Two weeks later his CSF WBC and CRAG had improved and 4 weeks later he was again asymptomatic with a normal opening pressure on follow-up lumbar puncture at week 6 (27 March, 1998). Today, he remains on fluconazole (200 $\mathrm{mg}$ daily) and is asymptomatic.

\section{Discussion}

Since the advent of HAART therapy, opportunistic infections with both atypical presentations and unusual clinical courses have been reported. We describe a patient with cryptococcal meningitis complicated by severe intracranial hypertension. After improving on appropriate therapy and after achieving an excellent virologic and immunologic response to HAART, the patient's symptoms and elevated intracranial pressure recurred. He improved clinically following lumbar puncture without altering his antifungal therapy. To our knowledge this is the first report of a patient developing the dangerous complication of elevated ICP during the course of immune reconstitution.

The phenomenon of immune reconstitution has been implicated in two clinical patterns of disease. First, opportunistic infections such as cytomegalovirus retinitis and mycobacterial lymphadenitis have appeared for the first time in patients recently started on HAART therapy [7, 8]. Alternatively, symptoms of a previously diagnosed opportunistic infection have been noted to recur while the patient is on adequate therapy and in the absence of positive cultures for the organism [9]. Most occurrences of immune reconstitution have been in patients whose CD4 cell counts, initially $<100 \mu \mathrm{l}^{-1}$, increased severalfold within a few weeks to months, presumably allowing a vigorous immune response to the infecting organism.

Several instances of immune reconstitution influencing the course of cryptococcosis have been reported previously [10-13]. Four patients who developed previously unrecognized cryptococcal infections (meningitis in three, lymphadenitis in one) only after initiation of HAART have been reported $[10,12,13]$. Three cases of cryptococcal lymphadenitis that occurred in patients receiving antifungal therapy for prior cryptococcal meningitis also have been described; all three recovered without changing their antifungal regimen [11, 13]. Two additional patients had a clinical picture similar to that of our patient; both had recurrence of meningeal signs and symptoms despite ongoing antifungal therapy $[10,12]$. Further data are available for only one of these two patients. Similar to our patient, this patient had negative CSF cryptococcal cultures and recovered without intensifying his treatment regimen; unfortunately, ICP was not assessed in this patient [10].

Elevated ICP is a serious but not uncommon complication of cryptococcal meningitis. In one recent study, $76 \%$ of 221 AIDS patients with cryptococcal meningitis had opening pressures $\geq 19 \mathrm{~cm} \mathrm{H}_{2} \mathrm{O}$, of which $27 \%$ were $\geq 35 \mathrm{~cm}$ $\mathrm{H}_{2} \mathrm{O}$ [5]. The group with severely elevated ICP had a significantly greater fungal burden as measured by CRAG titre. Those patients with ICP $\geq 25 \mathrm{~cm} \quad \mathrm{H}_{2} \mathrm{O}$ had shortened long-term survival; the prognosis worsened as the ICP increased.

The mechanisms leading to elevated ICP in cryptococcal meningitis are not definitively known. Obstructive hydrocephalus with enlarged ventricles is rare but can be caused by mass 
lesions, such as cryptococcomas. In most patients, however, ventricles are not enlarged on radiographic imaging despite the presence of elevated ICP, leading some to describe this as a pseudotumour cerebri-like syndrome [14, 15]. Obstruction of CSF outflow across the arachnoid villi or through lymphatic channels probably plays an important role and would be consistent with the presence of ventricles with normal appearance. This obstruction could be caused by the cryptococcal organism itself or aggregates of capsular polysaccharide [16]. Polysaccharide aggregates in the interstitial spaces may also alter CSF drainage leading to cerebral oedema [4, 14]. Lysis of the organism during antifungal treatment and the subsequent release of D-mannitol or capsular polysaccharide may increase the osmolality of the CSF and the interstitial fluid leading to a net influx of fluid $[5,16]$, although this has not been verified $[17,18]$.

Although no controlled trials have been conducted to link treatment of elevated ICP with improved survival, knowledge of the importance of ICP management in other conditions supports the aggressive management of ICP in this setting as well [19]. After obstructive hydrocephalus has been ruled out, initial treatment should include repeated lumbar punctures with the removal of high volumes of CSF. For patients in whom this manoeuvre is not adequate to control ICP, the use of temporary devices such as ventriculostomies or lumbar drains may be needed [5, 14]. A small number of patients may require placement of a permanent ventriculoperitoneal or lumboperitoneal shunt because of persistent intracranial hypertension $[14,20,21]$. In our patient, transient ventriculostomy drainage was adequate to control the initial symptoms and repeated high volume lumbar punctures successfully controlled his ICP when his symptoms recurred.

High-dose corticosteroid therapy appears to have little role in the management of increased ICP in AIDS patients with cryptococcal meningitis and in fact may be associated with clinical failure and early death [5]. Neither acetazolamide nor mannitol have been shown to be effective in the management of elevated ICP associated with cryptococcal meningitis and currently are not recommended [19].

This report documents elevated ICP as an important complication of immune reconstitution disease after cryptococcal meningitis and supports maintaining but not intensifying antifungal therapy. Physicians caring for patients with AIDS on HAART should be aware of this complication of cryptococcal infection and be prepared to monitor and aggressively treat elevated ICP in this setting.

\section{References}

1 Hajjeh, R. A., Conn, L. A., Stephens, D. S., et al. (1999 Cryptococcosis: population-based multistate active surveillance and risk factors in human immunodeficiency virusinfected patients. F. Infect. Dis. 179, 449-454.

2 Currie, B. P. \& Casadevall, A. (1994) Estimation of the prevalence of cryptococcal infection among patients infected with the human immunodeficiency virus in New York City. Clin. Infect. Dis. 19, 1029-1033.

3 Saag, M. S., Powderly, W. G., Cloud, G. A., et al. (1992) Comparison of amphotericin B with fluconazole in the treatment of acute AIDS-associated cryptococcal meningitis. $\mathcal{N}$. Engl. 7. Med. 326, 83-89.

4 Denning, D. W., Armstrong, R. W., Lewis, B. H. \& Stevens, D. A. (1991) Elevated cerebrospinal fluid pressures in patients with cryptococcal meningitis and acquired immunodeficiency syndrome. Am. 7. Med. 91, 267-272.

5 Graybill, J. R., Sobel, J., Saag, M., et al. (2000) Diagnosis and management of increased intracranial pressure in patients with AIDS and cryptococcal meningitis. Clin. Infect Dis. 30, 47-54.

6 Torres, R. A. \& Barr, M. (1997) Impact of combination therapy for HIV infection on inpatient census. $\mathcal{N}$. Engl. 7. Med. 336, 1531-1532.

7 Jacobson, M. A., Zegans, M., Ravan, P. R., et al. (1997) Cytomegalovirus retinitis after initiation of highly active antiretroviral therapy. Lancet 349, 1443-1445.

8 Race, E. M., Adelson-Mitty, J., Kriegel, G. R., et al. (1998) Focal mycobacterial lymphadenitis following initiation of protease-inhibitor therapy in patients with advanced HIV-1 disease. Lancet 351, 252-255.

9 Furrer, H. \& Malinverai, R. (1999) Systemic inflammatory reaction after starting highly active antiretroviral therapy in AIDS patients treated for extrapulmonary tuberculosis. Am. 7. Med. 106, 371-372.

10 Woods, M. L., MacGinley, R., Eisen, D. P. \& Allworth, A. M. (1998) HIV combination therapy: partial immune restitution unmasking latent cryptococcal infection. AIDS 12, 1491-1494.

11 Blanche, P., Gombert, B., Ginsburg, C., et al. (1998) HIV combination therapy: immune restitution causing cryptococcal lymphadenitis dramatically improved by antiinflammatory therapy. Scand. 7. Infect. Dis. 30, 615-616.

12 Michelet, C., Arviuex, C., François, C., et al. (1998) Opportunistic infections occurring during highly active antiretroviral treatment. AIDS 12, 1815-1822.

13 Lanzafame, M., Trevenzoli, M., Carretta, G., Lazzarini, L. Vento, S. \& Concia, E. (1999) Mediastinal lymphadenitis due to cryptococcal infection in HIV-positive patients on highly active antiretroviral therapy. Chest 116, 848-849.

14 Fessler, R. D., Sobel, J., Guyot, L., et al. (1998) Management of elevated intracranial pressure in patients with cryptococcal meningitis. 7. Acquir. Immune. Defic. Syndr. 17, $137-142$.

15 Cremer, P. D., Johnston, I. H. \& Halmagyi, G. M. (1997) Pseudotumor cerebri syndrome due to cryptococcal meningitis. 7. Neuro. Neurosurg. Psych. 62, 96-98.

16 Casadevall, A. \& Perfect, J. R. (1998). Cryptococcus Neoformans. Washington, DC, USA: ASM Press, pp. $494-496$. 
17 Megson, G. M., Stevens, D. A., Hamilton, J. R. \& Denning, D. W. (1996) D-Mannitol in cerebrospinal fluid of patients with AIDS and cryptococcal meningitis. f. Clin. Micro. 34, 218-221.

18 Malessa, R., Krams, M., Hengge, U., et al. (1994) Elevation of intracranial pressure in acute AIDS-related cryptococcal meningitis. Clin. Invest. 72, 1020-1026.

19 Saag, M. S., Graybill, R. J., Larsen, R. A., et al. (2000) Practice guidelines for the management of cryptococcal disease. Clin. Infect. Dis. 30, 710-718.
20 Bach, M. C., Tally, P. W. \& Godofsky, E. W. (1997) Use of cerebrospinal fluid shunts in patients in patients having acquired immunodeficiency syndrome with cryptococcal meningitis and uncontrollable intracranial hypertension. Neurosurgery 41, 1280-1283.

21 Mylonakis, E., Merriman, N. A., Rich, J. D., et al. (1999) Use of cerebrospinal fluid shunt for the management of elevated intracranial pressure in a patient with active AIDS-related cryptococcal meningitis. Diagn. Microbiol. Infect. Dis. 34, 111-114. 